\title{
Principales tendencias historiográficas sobre la organización militar visigoda del reino de Toledo
}

Main historiographical trends on the kingdom of Toledo's Visigoth military organization

\section{Sabrina Soledad Orlowski}

\section{OpenEdition}

\section{Journals}

Edición electrónica

URL: http://journals.openedition.org/medievalista/972

DOI: 10.4000/medievalista.972

ISSN: 1646-740X

Editor

Instituto de Estudos Medievais - FCSH-UNL

\section{Referencia electrónica}

Sabrina Soledad Orlowski, « Principales tendencias historiográficas sobre la organización militar visigoda del reino de Toledo », Medievalista [En línea], 19 | 2016, Puesto en línea el 01 junio 2016, consultado el 19 abril 2019. URL : http://journals.openedition.org/medievalista/972 ; DOI : 10.4000/ medievalista.972

\section{(C) IEM}


Título: Principales tendencias historiográficas sobre la organización militar visigoda del reino de Toledo I Main historiographical trends on the kingdom of Toledo's Visigoth military organization

Autor(es): Sabrina Soledad Orlowski

Universidade: Universidad Nacional de La Plata, Centro de Estudios de Historia Social Europea/IdHICS

Faculdade e Departamento / Unidade de Investigação: Facultad de Humanidades y Ciencias de la Educación

Código Postal:1923

Cidade: Berisso

País: Argentina

Contacto: sabrinaorlowski@hotmail.com

Fonte: Medievalista [Em linha]. Dir. Bernardo Vasconcelos e Sousa. Lisboa: IEM.

Disponível em:

http://www2.fcsh.unl.pt/iem/medievalista/MEDIEVALISTA19/orlowski1904.html

ISSN: 1646-740X

Data recepção do artigo: 8 de Janeiro de 2015

Data aceitação do artigo: 6 de Novembro de 2015

\section{Resumo}

El propósito de este trabajo es analizar las principales tendencias historiográficas sobre la organización militar visigoda. Haremos un repaso de los autores más influyentes y sus argumentos en torno al tema enunciado a fin de presentar los problemas más importantes. Es necesario repasar la producción historiográfica buscando demostrar que cada escuela realiza aportes significativos que no pueden ser desechados en las investigaciones empíricas actuales. Asimismo, demostraremos que existen presupuestos 
que han sido definidos en un momento historiográfico, cuyos argumentos han sido adoptados por las sucesivas generaciones de investigadores sin reflexión crítica.

Palavras-chave: Visigodo; reino de Toledo; ejército; historiografía; tendencias historiográficas

\section{Abstract}

The purpose of this paper is to analyze the main historiographical tendencies on the issue of the Visigothic military organization. We reviewed the most influential authors and their arguments within of this field in order to present its central topics of analysis. It is thus necessary to review the most important bibliography seeking to demonstrate that each trend of historical studies make very significant contributions that cannot be discarded in the current empirical research. Furthermore, we demonstrate that there are assumptions that have been defined in a particular historiographical moment, whose arguments have been adopted by successive generations of researchers without critical reflection.

Keywords: Visigoths; Kingdom of Toledo; Army; Historiography; Historiographical tendencies 


\title{
Principales tendencias historiográficas sobre la organización militar visigoda del reino de Toledo
}

\author{
Sabrina Soledad Orlowski ${ }^{1}$
}

\section{Introducción}

Diversas escuelas historiográficas, principalmente las españolas, intentan develar la organización y el funcionamiento del ejército visigodo del reino de Toledo. Las pocas fuentes disponibles hasta el momento ${ }^{2}$ (un conjunto de leyes, datos sueltos en crónicas y hagiografías, testimonios epigráficos y algunos cánones conciliares) y las fuertes proposiciones de los investigadores que guían el análisis dificultan el consenso entre los especialistas. Por supuesto que los estudios que analizaremos en este artículo se insertan en marcos interpretativos, pues se acuerda que existe una correspondencia entre la forma que adquiere el ejército y la sociedad. Desde la escuela institucionalista hasta las corrientes apoyadas en la literatura antropológica se ocupan del ejército visigodo, aunque no ha sido un tema de trabajos específicos desde la monografía de Dionisio Sánchez Pérez de $1989^{3}$ (a pesar del renovado interés del que ha sido objeto de análisis

\footnotetext{
${ }^{1}$ Quiero agradecer profundamente a los evaluadores de este artículo por sus aportes y sugerencias de cambios, que permitieron mejorar y profundizar este trabajo. Las devoluciones recibidas me generaron posibilidades de innovar y reflexionar sobre mi trabajo.

${ }^{2}$ PETERSEN, Leif, I - Siege warfare and military organization in the successor states (400-800). Byzantium, the West and Islam, (History of warfare; volume 91), Leiden-Boston: Brill, 2013. p. 165.

${ }^{3}$ El fichaje bibliográfico realizado por A. Ferreriro es una herramienta esencial para poder realizar dicha afirmación. FERREIRO, Alberto - The visigoths in Gaul and Spain (a.D. 418- 7I1). A bibliography, Leiden: Brill, 1988. FERREIRO, Alberto - The Visigoths in Gaul and Iberia. A Supplemental Bibliography, 1984-2003. - The Visigoths in Gaul and Iberia (Update). A Supplemental Bibliography, 2004-2006.- Brill Publishing (The Medieval and Early Modern Iberian World, 28 y 35).- Leiden-Boston, 2006. FERREIRO, Alberto - The Visigoths in Gaul and Iberia (Update). A Supplemental Bibliography,
}

Medievalista online № 19| Janeiro - Junho 2016 (c) IEM - Instituto de Estudos Medievais 3 
la Temprana Edad Media), solo es tratado como elemento subsidiario de análisis ${ }^{4}$, en manuales ${ }^{5}$, en estudios sobre la guerra en Europa durante la temprana Edad Media ${ }^{6}$, en estudios de alcance general ${ }^{7}$, y más recientemente en un libro que vincula las sociedades de la Península Ibérica de los siglos VII al XI con el ejército ${ }^{8}$.

A continuación haremos un repaso de los autores más influyentes y sus argumentos en torno al problema enunciado. Veremos que cada escuela realiza aportes significativos (sobre todo en lo relativo al estudio filológico y contextual de las leyes militares) que no pueden ser desechados sin miramientos en las investigaciones empíricas actuales Asimismo, demostraremos que existen presupuestos que han sido definidos en un momento historiográfico, cuyos argumentos han sido adoptados por las sucesivas generaciones de investigadores sin reflexión crítica.

En primer lugar, trataremos los argumentos de Sánchez Albornoz. El análisis de su obra nos posibilita desarrollar la doble tarea de observar sus argumentos y la de sus detractores y seguidores. En segundo lugar, examinaremos el legado de Barbero y Vigil y su continuidad en los autores vigentes. Por último, consideraremos las obras de origen extra hispana que tratan el problema de la organización del ejército utilizando conceptos antropológicos.

2007-2009. Leiden: Brill, 2011. FERREIRO, Alberto - The Visigoths in Gaul and Iberia (Update). A Supplemental Bibliography, 2010-2011. Leiden: Brill, 2014.

${ }^{4}$ DÍAZ MARTÍNEZ, Pablo. C - "La dinámica del poder y la defensa del territorio: para una comprensión del fin del reino visigodo de Toledo". in - XXXIX Semana de Estudios Medievales, de Mahoma a Carlomagno, Estella, 2012, pp. 167-205.

${ }^{5}$ DÍAZ MARTÍNEZ, Pablo - Hispania tardoantigua y visigoda. Madrid: Istmo, 2007.

LORING, María. I., PÉREZ, Dionisio. y FUENTES, Pablo - La Hispania tardorromana y visigoda., siglos V-VIII. Madrid: Editorial Síntesis, 2007.

${ }^{6}$ HALSALL, Guy - Warfare and society in the Barbarian West, 450-900. Londres: Routledge, 2003; PETERSEN, Leif. I - Siege warfare and military organization in the successor states (400-800). op. cit.

${ }^{7}$ WICKHAM, Chris - Una historia nueva de la Alta Edad Media, Europa y el mundo mediterráneo, 400800. Barcelona: Crítica, 2008. WICKHAM, C - El legado de Roma. Una historia de Europa de 400 al 1000. Barcelona: Ed. Pasado y Presente, 2013.

${ }^{8}$ ISLA FREZ, Amancio - Ejército, sociedad y política en la Península Ibérica entre los siglos VII y XI. Madrid: CSIC, 2010.

Medievalista online № 19| Janeiro - Junho 2016 ๑ IEM - Instituto de Estudos Medievais 4 


\section{Sánchez Albornoz, el ejército y la protofeudalización de un reino}

En la década de 1920, Torres López publica un extenso artículo cuyo fin principal es demostrar la existencia de un estado visigótico sustentado en el derecho público sin absorción del poder político por parte de particulares; según su propuesta, el principio de utilidad pública se materializaba, por ejemplo, en la convocatoria del ejército realizada por el rey para la defensa del reino. Su concepción política del estado, que tiene como base "la no existencia de la personalidad del poder" y "el vigor del concepto del derecho"10, conlleva a una relación política de súbdito general, negando cualquier tipo de sumisión de carácter absoluta o patrimonial al rey godo ${ }^{11}$. Con este marco interpretativo lleva a cabo el estudio de los términos leudes y fideles. La exégesis de la ley IV.5.5 le permite concluir que el vocablo leudes designaba a todos los súbditos en general que participaban de la guerra; comparando los numerosos pasajes legislativos sostiene que el término fideles $^{12}$ es sinónimo de súbdito leal, no lo identifica como vasallo del rey que recibe beneficios de éste, niega la existencia de "una especial relación del rey con algunos súbditos ligados por fidelidad especial"13. Años más tarde, Sánchez Albornoz contesta punto por punto los planteos de Torres López desarrollando su propia tesis sobre reino de Toledo, logrando imponer su visión de la sociedad goda hasta la aparición de los estudios de Barbero y Vigil en la década de 1970.

Como es harto conocido, Sánchez Albornoz sostiene que la sociedad visigoda fue una sociedad protofeudal ${ }^{14}$; el estudio del ordenamiento del ejército es central en su

\footnotetext{
9 TORRES LÓPEZ, Manuel - “El estado visigótico”. Anuario de Historia del Derecho Español, T.III, 1926, pp. 304-475, p. 375.

${ }^{10}$ TORRES LÓPEZ, Manuel - "El estado visigótico”. op. cit. p. 375.

11 TORRES LÓPEZ, Manuel - "El estado visigótico". op. cit., p. 426.

12 Utiliza las leyes: VI, I,6; III,5,3; IX,2,9; II,5,19; IX,2,8; XII,1,2. TORRES LÓPEZ, Manuel - "El estado visigótico". op. cit. p. 430 y ss.

${ }^{13}$ TORRES LÓPEZ, Manuel - "El estado visigótico". op. cit. p. 439.

14 Ver: SÁNCHEZ ALBORNOZ, Claudio - En torno a los orígenes del feudalismo. Mendoza, 1942; "Pervivencia y crisis de la tradición jurídica romana en la España goda", en Viejos y nuevos estudios sobre las instituciones medievales españolas. II, Madrid, 1976; "El precarium en Occidente durante los primeros siglos medievales". Viejos y nuevos estudios sobre las instituciones medievales españolas. II, Madrid, 1976; El «Stipendium»Hispano-Godo y los orígenes del beneficio prefeudal. Buenos Aires: Instituto de Investigaciones Históricas. Departamento de Historia de España, 1947; "España y el feudalismo carolingio". Viejos y nuevos estudios sobre las instituciones medievales españolas. II, Madrid,
}

Medievalista online № 19| Janeiro - Junho 2016 (c) IEM - Instituto de Estudos Medievais 5 
argumentación. Veamos los principales puntos en relación a la organización y composición del ejército, partes centrales de su tesis.Propone que los visigodos introdujeron el deber y el derecho de todos los hombres libres y aptos de concurrir a la guerra $^{15}$, aunque la incorporación de los provinciales romanos a las filas militares fue algo posterior sin poder fecharla con exactitud por la parquedad de las fuentes ${ }^{16}$. Dedica varias páginas al problema del aprovisionamiento de las armas, no por estar preocupado solamente por los tipos de pertrechos sino porque su distribución la relaciona con la perpetuación de la organización militar germánica en el reino de Toledo, que vinculaba la libertad de los hombres con la posesión de armas. El examen de las leyes IX.2.1-6 le permite afirmar la existencia de una organización de tipo decimal ${ }^{17}$ heredada de los tiempos romanos; los potenciales hombres en armas se encontraban encuadrados en thiufas, centenas y decanías, conformando un conjunto anterior a la reunión del ejército convocada por el rey ${ }^{18}$. Considera de suma importancia la división del ejército en caballería e infantería, pues de seguro los fideles y gardingos y otros miembros de la nobleza combatían a caballo. Aquí llegamos al punto substancial de su planteo. Observa que aquellos que mantuvieron un vínculo personal con el rey y cumplieron un deber militar superior al resto de los hombres libres recibían tierras con el fin de mantener sus unidades de caballería especializadas para entrar en la guerra, y aquí es donde encuentra el origen de la protofeudalización del ejército, haciendo eco de las críticas realizadas a

1976; “Donaciones reales restringidas en la España goda y postvisigoda?” Separata Homenaje a Don José María Lacarra de Miguel en su jubilación del profesorado. Vol. I, Zaragoza 1977.

${ }^{15}$ SÁNCHEZ ALBORNOZ, Claudio - "El ejército visigodo: su protofeudalización". Investigaciones y documentos sobre las instituciones hispana. Santiago: Edit. Jurídica de Chile, 1970, pp. 5-56. p. 7.

${ }^{16}$ SÁNCHEZ ALBORNOZ, Claudio - "El ejército visigodo: su protofeudalización". op.cit, p. 10. Torres López sostiene que desde los tiempos de Eurico los hispanorromanos se incorporaron al ejército godo. VER: TORRES LÓPEZ, Manuel - Lecciones de historia del Derecho. Salamanca, 1934, p. 23. ORLANDIS, José - Historia del reino visigodo español. Madrid: RIALP, 2011, p. 168. Thompson considera que los romanos siempre se sintieron diferentes. THOMPSON, Edward. A - The Goths in Spain. Oxford: Oxford University Press, 1969, p. 146. Por su parte King cree probable que después de la unificación religiosa los romanos eran incorporados al ejército, pero es difícil decir con exactitud desde qué fecha. KING, P.D - Derecho y sociedad en el reino visigodo. Madrid: Alianza, 1972. p. 92)

${ }^{17}$ Idea aceptada por KING, P.D - Derecho y sociedad en el reino visigodo...op. cit, p. 93, ORLANDIS, José - Historia del reino visigodo español p. 169 y 170. MARTIN, Céline -La géographie du pouvoir dans l'Espagne visigothique. Francia : Universitaires du Septentrion, 2003, p. 153.

${ }^{18}$ SÁNCHEZ ALBORNOZ, Claudio -“El ejército visigodo: su protofeudalización”. op. cit. p. 26 y ss.

Medievalista online № 19| Janeiro - Junho 2016 (c) IEM - Instituto de Estudos Medievais 6 
Brunner por Dospch ${ }^{19}$. Para sostener lo dicho, analiza el famoso pasaje de la Vita Fructuosi. Allí se describe el pedido que realiza el cuñado de Fructuoso al rey de una parte de las heredades del monasterio, que el santo presidía, para que a él quasi pro exercenda publica expeditione conferretur ${ }^{20}$. Defiende que el duque de la familia de Fructuoso no peticionó la entrega de la propiedad a fin de realizar una sola expedición, puesto que por la prescripción de las leyes estaba obligado a acudir siempre, sino para prestar una asistencia especial; solicitó un beneficio militar para servir como caballería en la guerra. Para Sánchez Albornoz, no debe sorprender que se hayan generalizado las figuras jurídicas de las concesiones de tierra causa stipendi por servir a caballo ${ }^{21}$. En relación a esto, constata la participación de un número significativo de siervos en las batallas recién para mediados del siglo VII, como lo dispone la ley de Ervigio IX.2.9, fenómeno que posee su origen en el acrecentamiento del poder de la nobleza debido a su arraigo a la tierra, fenómeno alentado por la entrega de beneficios militares realizados por los reyes ${ }^{22}$. El autor abulense observa que "las viejas ideas del ejército popular germánico habían dado paso a una fuerza armada constituida, en parte, por masas en relación de dependencia personal con los miembros de los clanes que integraban las más elevadas estructuras sociales del reino"23.

19 DOPSCH, Alfons - Fundamentos económicos y sociales de la cultura europea (de César a Carlomagno). México: Fondo de Cultura Económica, 1986, pp. 385 y ss. Barbero y Vigil ya señalan la fuerte influencia del alemán sobre Sánchez Albornoz. Estos autores critican fuertemente tanto a Dopsch como al abulense al señalar: "Dopsch y Sánchez Albornoz adolecen de los mismos defectos metodológicos que Brunner, al admitir que la génesis del feudalismo depende en concreto de un hecho militar tan problemático como es la divulgación de la forma de guerrear a caballo", BARBERO, Abilio \& VIGIL, Marcelo - La formación del feudalismo en la Península Ibérica. Barcelona: Crítica, 1978, p. 160.

${ }^{20}$ SÁNCHEZ ALBORNOZ, Claudio -“El ejército visigodo: su protofeudalización”. op. cit. p. 39 y En torno a los orígenes del feudalismo. op. cit. pp. 168-173.

${ }^{21}$ SÁNCHEZ ALBORNOZ, Claudio - "El ejército visigodo: su protofeudalización”. op. cit. p. 42.

${ }^{22}$ Declara: "Sólo más tarde, tal vez en las postrimerías de la historia hispanogoda, al arraigar en la tierra los potentes visigodos e incorporarse al ejército los romanos poderosos y al aumentar la población servil del reino, fue preciso decretar la obligación de todos los dueños de siervos de acudir a campaña con una parte de los suyos y no inermes sino bien armados. Pero esos decretos como otros procesos históricos sincrónicos, fueron, sobre todo, consecuencia de lo que podríamos llamar protofeudalización del Estado y, por ende, del ejército hispanovisigodo". Ibidem, p. 30. Thompson y Arce consideran que el ejército godo del reino tuvo un fuerte componente servil. THOMPSON, Edward. A -The goths in Spain. op. cit. p. 262. ARCE, Javier -Esperando a los árabes: los visigodos en Hispania (507-711). Madrid: Marcial Pons Historia, 2011, p.127.

${ }^{23}$ SÁNCHEZ ALBORNOZ, Claudio -“El ejército visigodo: su protofeudalización”. op. cit. p. 38. 
Los planteos de Sánchez Albornoz tuvieron un recibimiento muy importante en el mundo académico ${ }^{24}$, ejemplo de esto es el libro de P.D. King (aunque mantienen algunas diferencias, por ejemplo la interpretación de la ley sobre leudes ${ }^{25}$ ), muy citado entre los visigotistas que comulgan con la tesis que identifica a la monarquía visigoda como teocrática. Este autor considera que las obligaciones militares de los nobles contraídas para con el rey (consecuencia de sus vínculos de fidelidad) debían ser muy costosas, justificando plenamente la concesión de tierras ${ }^{26}$. Sostiene que el control de las tropas fue una prerrogativa del rey quien reunía y disolvía el ejército y comandaba personalmente o delegaba su mando a un tercero. Estudiando la ley de administración militar IX, 2, 6, observa la existencia de un ejército permanente en complejos de castra, aunque no le resulta verosímil la existencia de una guarnición en cada una de las ciudades; el aprovisionamiento de este ejército estaba a cargo de un annonarius (constatado en la ley IX, 2, 6) y bajo órdenes del dux exercitus provinciae y, en una escala inferior, del tiuphadus. Sin embargo, sostiene que los fideles regis y los gardingi no se encontraban bajo las órdenes de los oficiales; estos magnates mandaban a sus propios seguidores en las batallas, los bucellarii y saiones ${ }^{27}$.

Tanto Sánchez Albornoz como King utilizan el cuerpo legislativo como principal fuente de investigación, lo cual los lleva a admitir la imposibilidad de realizar de forma más acabada un estudio más completo. En ambos casos sus preocupaciones particulares acotan los problemas a campos de estudios limitados.

\section{El ejército feudal visigodo: reflejo de la sociedad}

Desde otra perspectiva historiografía, Barbero y Vigil en sus estudios consideran que en el reino de Toledo las relaciones de dependencia y subordinación del campesinado fue la norma general, y este tipo de organización social se expresó en las instituciones

\footnotetext{
${ }^{24}$ Orlandis sigue los argumentos del maestro abulense. ORLANDIS, José - Historia del reino visigodo español. op.cit p. 168 y ss.

${ }^{25}$ KING, P.D - Derecho y sociedad en el reino visigodo. op. cit. p 77, n. 29.

${ }^{26} \mathrm{KING}, \mathrm{P} . \mathrm{D}$ - Derecho y sociedad en el reino visigodo. op. cit. p. 92 y ss.

${ }^{27}$ KING, P.D - Derecho y sociedad en el reino visigodo. op. cit. p. 95.
} 
políticas, jurídicas y en el sistema ideológico ${ }^{28}$. En contra de la historiografía jurídicainstitucional, rechazan la idea de identificar la protofeudalización del reino visigodo con la organización militar, pues sostienen que el ejército reproduce las características principales de la sociedad. Constatan la existencia formal de un ejército público, aunque su composición social varió de una época a otra. Consideran que la sujeción de los campesinos a la tierra, que se extendió de forma dominante, perjudicó seriamente las finanzas estatales y sus posibilidades de mantener un ejército público, a la vez que alimentó los ejércitos privados de los grandes propietarios; por lo tanto, en el siglo VII eran los ejércitos privados los convocados a cumplir las funciones públicas ${ }^{29}$. Las filas militares estaban compuestas tanto por hombres libres como por siervos; observan que el campesinado (a pesar de las diferencias jurídicas existió una homogeneización económica) cumplía con el servicio militar como "una prestación personal más que debía al señor, poniéndose de relieve así su analogía con las prestaciones de trabajo y la forma de uso de la tierra dentro de un marco general de obligaciones personales de dependencia" ${ }^{, 30}$. Por otra parte, las obligaciones militares de la nobleza para con el rey son entendidas como "prestaciones políticas"31 encuadradas en el régimen general de fidelidad.

Una vez puestas en tensión los argumentos de Sánchez Albornoz por Barbero y Vigil, la historiografía discutió durante gran parte del siglo XX sobre la naturaleza feudal o protofeudal de la sociedad visigoda, y por lo tanto del ejército. Por lo general, los historiadores contemporáneos se adscriben de forma general a una u otra matriz explicativa, por ejemplo L.A García Moreno, sostiene que para mediados del siglo VII las fuerzas militares del reino estaban constituidas por clientelas privadas bajo mando

\footnotetext{
${ }^{28}$ BARBERO, Abilio. y VIGIL, Marcelo - La formación del feudalismo en la Península Ibérica. op. cit. p. 41.

${ }^{29}$ BARBERO, Abilio. y VIGIL, Marcelo - La formación del feudalismo en la Península Ibérica. op. cit. p. 44.

${ }^{30}$ BARBERO, Abilio. y VIGIL, Marcelo - La formación del feudalismo en la Península Ibérica. op. cit. p. 52.

${ }^{31}$ BARBERO, Abilio. y VIGIL, Marcelo - La formación del feudalismo en la Península Ibérica. op. cit. p. 52.
}

Medievalista online № 19| Janeiro - Junho 2016 ๑ IEM - Instituto de Estudos Medievais 9 
directo de un reducido número de nobles laico y eclesiásticos ${ }^{32}$, situación que respondía al avanzado estado de feudalización de los lazos de dependencia. Con raras excepciones $^{33}$, en la bibliografía de origen español la corriente historiográfica fundada por Barbero y Vigil sigue imponiéndose, encerrando en la tesis de un feudalismo visigodo a muchos de los especialistas ${ }^{34}$.

Dionisio Pérez Sánchez en un exhaustivo trabajo sobre el ejército visigodo ${ }^{35}$ analiza la evolución de la organización militar desde el siglo IV hasta el VII, estableciendo una correspondencia entre el carácter del ejército y la organización social. Advierte que en el siglo VI se encuentra un cuerpo militar regular cuya organización es decimal y profesional $^{36}$, en convivencia con bandas armadas dependientes de los grandes propietarios que cumplían funciones públicas. Para el siglo VII, ambos tipos de ejércitos coexistían, pero las tropas privadas ganaron primacía llegando a absorber al ejército

${ }^{32}$ GARCÍA MORENO, Luis, A - Historia de España visigoda. Madrid: Cátedra, 1989, p. 177 y ss.

33 En el sentido contrario, Salrach considera que los ejércitos de los reinos romano-germánicos se componían "por un sólo ejército público, a las órdenes de un poder único, el rey, que para su funcionamiento puede utilizar canales privados" En: SALRACH, Joseph. M - "Del estado romano Principales tendencias historiográficas sobre la organización militar visigoda del reino de Toledo a los reinos germánicos: en torno a las bases materiales del poder del estado en la antigüedad tardía y la Alta Edad Media". in De la antigüedad al Medievo: siglos IV-VIII. 1993, pp. 95-152, pp. 128-129. Por su parte, Céline Martin, con una posición historiográfica "continuista", cree en el carácter público del ejército y en la delegación del poder regio en agentes territoriales de la monarquía, incluyendo el mando militar; según su marco interpretativo general, esta delegación del poder no significa que el poder regio estatal se divida o tienda a pulverizarse, todo lo contrario, en esos agentes se multiplica haciendo al estado más fuerte MARTIN, Céline-Lagéographie du pouvoir dans l'Espagne visigothique. op. cit. pp. 151-203 (en especial pp. 176-180).

${ }^{34}$ Entre los referentes cuyas obras no se analizan aquí: $M^{\text {a }}$ Isabel Loring, Pablo Fuentes Hinojo, Renan Frighetto. LORING, María, I. y FUENTES HINOJO, Pablo -"Esclavitud y servidumbre en el tránsito del mundo antiguo al medieval". in - "Romanización" y "reconquista" en la Península Ibérica: nuevas perspectivas, 1998, pp. 247-256; En el año 2007 editan en conjunto un libro el cual encierra los núcleos principales de cada uno de sus artículos: LORING, María, I., PÉREZ, Dionisio. y FUENTES, Pablos - La Hispania tardorromana y visigoda. Siglos V-VIII. Madrid: Editorial Síntesis, 2007. FRIGHETTO, Renan - "O problema da legitimidade e a limitaçao do poder régio na Hispania visigoda: o reinado de Ervígio (608-687)". in -Gerión, 2004, n 1, pp 421-435.; "Infidelidade e Barbárie na Hispania Visigoda". in Gerión, Vol. 20, N 1, 2002, pp. 491-510. Es lícito mencionar que este último autor hace referencia a un "proto-feudalismo", sin embargo consideramos pertinente incluirlo dentro de los seguidores de la tesis de Barbero y Vigil, pues utiliza como apoyo bibliográfico la obra de $\mathrm{M}^{\mathrm{a}}$ Rosario Valverde Castro y Pablo C. Díaz, quienes explícitamente continúan considerando feudal a la sociedad visigoda.

35 PÉREZ SÁNCHEZ, Dionisio - El ejército en la sociedad visigoda. Salamanca: Ediciones de la Universidad de Salamanca, 1989.

${ }^{36}$ PÉREZ SÁNCHEZ, Dionisio - El ejército en la sociedad visigoda. op. cit. p. 117.

Medievalísta online № 19| Janeiro - Junho 2016 (C) IEM - Instituto de Estudos Medievais 10 
público $^{37}$. Finalmente, el autor sostiene que ejército visigodo (al mando del rey o un magnate) fue el resultado de la suma de las tropas compuestas por los dependientes de los nobles. Estas tropas podían cumplir indistintamente el servicio público como las tareas pedidas por su señor, inclusive si esto incluía enfrentar al mismo $\mathrm{rey}^{38}$. En conclusión, para este autor la organización militar del siglo VII es reflejo del sistema feudal, de la atomización sociopolítica del reino godo.

Otra historiadora que se enfila detrás de la tesis del feudalismo visigodo es Valverde Castro. Su análisis sobre el ejercicio del poder regio se centra en los elementos teóricos y simbólicos y en las limitaciones prácticas existentes a este poder. Sostiene que los reyes mantienen su carácter de jefe guerrero, lo cual se manifiesta en el reconocimiento como jefe supremo del ejército $^{39}$; la teoría política-religiosa legítima los poderes militares regios. Un elemento de análisis interesante que destaca la autora (ya detectado por Orlandis pero sin desarrollar ${ }^{40}$ ) es el desarrollo de la simbología de la supremacía militar del rey. También destaca que se mantiene la concepción pública del ejército, sin embargo, el poder militar del rey se encontraba limitado por la imposibilidad real de hacer cumplir a los nobles con las obligaciones militares que las leyes indicaban, lo que se traduce en la desaparición del carácter público del ejército, todo en un “(...) claro proceso de feudalización(...)" ${ }^{\text {41 }}$.

Recientemente, Pablo Díaz describió al ejército visigodo de fines del siglo VII como un ejército formado en su amplia mayoría por milicias rurales poco entrenadas dependientes de los grandes propietarios y por cuerpos armados profesionales

\footnotetext{
${ }^{37}$ PÉREZ SÁNCHEZ, Dionisio - El ejército en la sociedad visigoda....op. cit. p. 129 y ss.

${ }^{38}$ PÉREZ SÁNCHEZ, Dionisio - El ejército en la sociedad visigoda....op. cit. p. 136.

${ }^{39}$ VALVERDE CASTRO, María. R - Ideología, simbolismo y ejercicio del poder real en la monarquía visigoda: un proceso de cambio. Salamanca: Ediciones de la Universidad de Salamanca, 2000,pp. 233236.

${ }^{40}$ ORLANDIS, José - Historia del reino visigodo español. op. cit. p. 167. Este autor detecta que la imagen del rey-caudillo deja su marca en la liturgia hispana y en la Hymnodia Gotica.

${ }^{41}$ VALVERDE CASTRO, María, R - Ideología, simbolismo y ejercicio del poder real en la monarquía visigoda: un proceso de cambio. op. cit. p. 236.
} 
vinculados a los gardingos y a la aristocracia del palacio; se sumaban a estos últimos las tropas de elite bajo el comando del comes spathariorum ${ }^{42}$.

Isla Frez, en el mismo carril argumentativo que Díaz, añade que las huestes, conformadas en gran medida por propietarios y sus guerreros, mantienen un vínculo personal con los duces y comes, (seniores ${ }^{43}$ que contribuyen con sus dependientes a la formación del ejército regio) antes que un nexo de fidelidad con el rey.

Como es evidente, los autores reseñados se enmarcan en la tesis del feudalismo visigodo propuesto por Barbero y Vigil; aceptando la dependencia extendida presuponen, por lo tanto, que los soldados, a pesar de la heterogeneidad de las condiciones jurídicas, mantienen un fuerte vínculo de dependencia con algún noble terrateniente; como consecuencia todo indicio documental sobre vínculos o encomiendas personales de tipo militar lo entienden en clave feudal. Es justo decir también que resultan interesantes los argumentos de los autores sobrela composicióndel ejército formadas por milicias rurales/ élites entrenadas privadas y su forma de agregación al ejército regio siguiendo a un cabecilla aristócrata (en especial con los planteos de Díaz e Isla Frez), aunque su matriz explicativa central que remite a una sociedad en un claro proceso de segmentación feudal, donde existe un reparto regional de poderes políticos y económicos y los grandes propietarios controlan extensas zonas y a sus habitantes $^{44}$ está en plena revisión ${ }^{45}$.

42 DÍAZ MARTÍNEZ, Pablo. C - "La dinámica del poder y la defensa del territorio: para una comprensión del fin del reino visigodo de Toledo". op. cit. p.189.

${ }^{43}$ ISLA FREZ, Amancio - Ejército, sociedad y política en la Península Ibérica entre los siglos VII y XI. op. cit. p. 84.

${ }^{44}$ ISLA FREZ, Amancio - Ejército, sociedad y política en la Península Ibérica entre los siglos VII y XI. op. cit. p. 228; DÍAZ MARTÍNEZ, Pablo. C - "La dinámica del poder y la defensa del territorio: para una comprensión del fin del reino visigodo de Toledo". op. cit. p. 187.

${ }^{45}$ Ver: COLLINS, Roger - La España Visigoda 409-711. Barcelona: Crítica, 2005, p. 8 y ss. 


\section{Las relaciones sociales en el interior de la organización militar analizadaspor la historiografía extra-hispana}

La historiografía altomedieval de los últimos años ha comenzado a sintetizar este periodo revelando categorías analíticas nuevas que permiten pensar la especificidad de la temprana Edad Media en su propia lógica de funcionamiento, y enfatizando la visión de Europa como totalidad en oposición a los enfoques locales concordantes con la historia nacionalista ${ }^{46}$. Esta corriente renovadora ha impulsado estudios sobre la guerra y la organización de los ejércitos de los estados sucesores del Imperio Romano. A continuación nos ocuparemos sobre autores no españoles que tratan el problema de la guerra desde diferentes ángulos y con perspectivas historiográficas renovadas ${ }^{47}$, excepto cuando tratan el caso visigodo.

Hace ya más de una década, en un estudio notable Halsall analiza la relación entre la guerra y la sociedad en Europa occidental entre los años 500 y $900^{48}$; a pesar de su carácter general, los argumentos expuestos son interesantes para empezar a pensar el funcionamiento del ejército visigodo desde una perspectiva renovada. En su opinión, a lo largo del siglo VI y en las primeras décadas del VII la naturaleza del ejército en los territorios post romanos experimentó una serie de transformaciones al ritmo del desarrollo socioeconómico. En un primer momento, los jefes bárbaros se convirtieron

\footnotetext{
${ }^{46}$ Se oponen a enfoqueslocalistas, entre otros: ASTARITA, Carlos - "Visiones nacionales en el medievalismo". in - Anales de Historia Antigua, Medieval y Moderna. Buenos Aires, 2008, vol. 40, pp. 119-150, WICKHAM, Chris - "Tradiciones nacionales y el problema de la comparación". in Anales de Historia Antigua, Medieval y Moderna.Buenos Aires, 2008, vol. 40, pp. 11-24. Este autor considera que "Los historiadores europeos que no comparan casi siempre estudian su propio país, y esa atención reconcentrada sobre su espacio crea una Europa - un mundo- de islas, sin relación entre sí, en cada una de las cuales no sólo los patrones del cambio social sino también las preguntas que los historiadores formulan son absolutamente distintivas. Para empeorar las cosas estos aislamientos se corresponden, en casi todos los casos, con teleologías nacionales". Ch. Wickham consideraestocomo un solipsismo cultural, p. 11. Un primer acercamiento a este problema lo encontramos en WICKHAM, Chris "Problems of comparing rural societies in early medieval western Europe". in Land \& Power, Studies in Italian and European Social History, 400-1200. London: British School at Rome, 1994, p. 201 y ss; Versión en español: "Problemas de comparación de sociedades rurales en la Europa occidental de la temprana Edad Media". in -Anales de Historia Antigua y Medieval, Buenos Aires, 1996, vol. 29, pp. 45 y ss.

${ }^{47}$ Por ejemplo: PETERSEN, Leif, I. - Siege warfare and military organization in the successor states (400-800). op. cit. SMITH, Katherine, A. - War and the Making of Medieval Monastic Culture. Suffolk: The Boydell Press, 2013.

${ }^{48}$ HALSALL, Guy - Warfare and society in the Barbarian West, 450-900. op. cit.
}

Medievalísta online $N^{\circ}$ 19| Janeiro - Junho 2016 @ IEM - Instituto de Estudos Medievais 13 
en reyes de sus pueblos, generales de los ejércitos otrora romanos, se asentaron sobre las tierras y consolidaron sus posiciones con su reparto. La identidad étnica bárbara subsumió a todo lo considerado romano, convirtiéndose en un factor tan determinante que los romanos debieron pagar los impuestos y los bárbaros ir a la guerra. En el tardío siglo VI, fue cada vez más común la asociación del estatus de libre con la identidad étnica, y lentamente y como consecuencia de los cambios sociales (la aristocracia se fue fortaleciendo afianzando su posición sobre la tierra y sobre el resto de la población que comenzó a caer bajo su dependencia) los ejércitos compuestos de guerreros identificados con una etnia particular descendientes de las tropas de campaña tardorromanos trasmutaron en ejércitos organizados e integrados por poseedores de tierras $^{49}$.

Halsall concluye que las instituciones militares que sobrevivieron a la caída del sistema romano (en el caso visigodo la división decimal, la oficina encargada de la leva militar) fueron transformándose hasta tal punto que hacia el 700 el ejército regular pago dejó de existir. Si bien la disposición que señalaba que los hombres libres tenían la obligación de hacer la guerra continuó, en la práctica el ejército estaba compuesto por poderosos terratenientes y sus dependientes. Esta aristocracia de cultura militar retenía en teoría títulos por el servicio regio; esta legitimación regia del poder aristocrático fue un cambio fundamental. A comienzos del siglo VIII era el poder aristocrático quien ordenaba a los guerreros que mantenían una relación de dependencia.

En el caso puntual de la organización del ejército visigodo, Halsall cuestiona la existencia de un ejército permanente para el siglo VII, más bien considera que la ley que dispone sobre el almacenamiento de los víveres para los ejércitos (IX.2.6) se refiere al suministro de las tropas de paso por las ciudades o castella; como King ${ }^{50}$, no considera que en cada complejo de castra y fortalezas hubiese podido existir una guarnición de tropas permanente por su alto costo del abastecimiento, aunque sí cree en la permanencia de tropas disponibles para la salvaguarda del rey y los oficiales, pero estos

\footnotetext{
${ }^{49}$ HALSALL, Guy - Warfare and society in the Barbarian West, 450-900. op. cit. pp. 40-70.

${ }^{50}$ KING. P.D - Derecho y sociedad en el reino visigodo. op. cit. p. 92.
} 
no componían elementos suficientes para ser llamados ejército. Las leyes militares promulgadas por Wamba y Ervigio le estimulan a pensar que el servicio militar constituía una obligación de todos los hombres y propone que las respectivas leyes, sobre todo la de Ervigio, operan sobre "a chain of lordship and clientship" conclusión la realiza analizando el contexto legislativo y político visigodo: en referencia a lo primero, la preocupación por ordenar las relaciones entre patrones y patrocinados fue constante; en cuanto al segundo aspecto, las turbulencias alrededor del trono promovieron una legislación para obligar a la aristocracia a cumplir sus deberes militares. Afirma que los séquitos aristocráticos constituyeron la base de organización del ejército godo, esto le revela similitudes con las zonas del norte de los Pirineos.

En el marco de las observaciones anteriores, Halsall considera que la evolución de un ejército regular a uno compuesto por los dependientes de la aristocracia en Hispania es similar, si no igual, a las transformaciones experimentadas por los francos; esta comparación le permite sostener que esta metamorfosis en lo militar no implicó automáticamente un debilitamiento del poder regio ${ }^{52}$. Sin embargo, y a pesar de los esfuerzo por mantener la unidad del reino desde lo político e ideológico, sugiere que los reyes visigodos no tuvieron la fuerza suficiente para penetrar en las sociedades locales con el fin de crear una situación en la cual la preeminencia social dependiese en gran medida de los favores regios.

Como podemos observar, la línea de tiempo evolutiva de la composición y organización de los ejércitos en los reinos sucesores al Imperio Romano no difiere demasiado de los autores ya estudiados. Sin embargo, el aporte más significativo a nuestro entender es la caracterización que realiza Halsall sobre la relación entre los guerreros y la aristocracia. Señala correctamente que existe una cadena de mando "vertical" entre estos dos sujetos sociales que debe ser entendida como una relación social laxa, que podía involucrar donaciones de tierras y promesas de lealtad pero sin contenido de formalidad alguna, y menos de legalidad. Estas redes eran personales y muy a menudo informales; las

\footnotetext{
${ }^{51}$ HALSALL, Guy - Warfare and society in the Barbarian West, 450-900. op. cit. p. 61

${ }^{52}$ HALSALL, Guy - Warfare and society in the Barbarian West, 450-900. op. cit. p. 63
}

Medievalista online № 19| Janeiro - Junho 2016 @ IEM - Instituto de Estudos Medievais 15 
recompensas entregadas podían ser bienes muebles o intangibles, como el apoyo en disputas o en casos legales ${ }^{53}$.

Todo balance historiográfico que trate sobre algunos de los aspectos de la Temprana Edad Media debe hacer referencia a los argumentos de Wickham. En cuanto a la organización del ejército visigodo, el británico sostiene explicaciones similares a las expuestas más arriba: en el reino de Toledo el ejército romano asalariado había desaparecido dando paso a un ejército "basado en la obligación pública de ingresar en sus filas" $" 54$. Siguiendo las leyes que hacen referencia a los clientes, sugiere que los magnates tuvieron a su cargo soldados que no integraban ningún ejército regular, debían seguir al duque, al conde o al patronus ${ }^{55}$ y recibían tierras a cambio de sus servicios.

Si bien el análisis de Wickham sobre el caso visigodo se encuentra dentro de los parámetros historiográficos conocidos, los elementos destacados en su examen sobre las estructuras políticas de Europa del Norte resultan interesantes porque demuestra lo conveniente que puede ser incorporar elementos provenientes de la antropología (además que posibilita un nuevo universo para caracterizar el rol de los reyes visigodos como jefes guerreros no solo desde el plano simbólico como se ha hecho sino desde el ejercicio del liderazgo concreto, una hipótisis para ser explorada en el futuro). Por estos motivos incluimos una breve caracterización de este autor sobre aquella región.

Considera que la sociedad norteña se encontraba débilmente jerarquizada; los productores agrícolas eran autónomos y la aristocracia dominó una pequeña fracción del campesinado, los unos y los otros convivían manteniendo relaciones en términos de obediencia y tributos, tal vez simbólicos. Asimismo, constata un dominio formal del rey sobre grandes extensiones de tierra, donde no comprueba la extracción regular de rentas sino de forma marginal. A pesar de que la aristocracia como conjunto es relativamente estable (se constata la transmisión hereditaria de la riqueza), su dominación sobre las clases productoras era incompleta, puesto que el poder aristocrático se sustentaba en

\footnotetext{
${ }^{53}$ HALSALL, Guy - Warfare and society in the Barbarian West, 450-900. op. cit. p.56.

${ }^{54}$ WICKCHAM, Chris - Una historia nueva de la alta edad media. op. cit. p. 168.

${ }^{55}$ WICKCHAM, Chris - Una historia nueva de la alta edad media. op. cit. p. 168.
} 
relaciones de reciprocidad (y no sobre la base de la territorialidad) y su liderazgo respondía más a los parámetros del carisma que a un poder basado en derechos exclusivos sobre la tierra: los jefes locales debían procurar que sus seguidores no cambien su lealtad, y se vinculaban con los hombres libres mediante fórmulas laxas (banquetes, intercambio de regalos, etc.). Cabe agregar que la riqueza se distribuía en sentido descendente, desde los caudillos hasta los clientes; este comportamiento explicaría la escasa concentración de riqueza material en los hallazgos arqueológicos. La realeza no estaba exenta de este comportamiento, lo cual ha llevado a pensar a los reges temprano medievales del norte europeo como caudillos de hombres libres con bases materiales restringidas ${ }^{56}$.

A pesar de las grandes diferencias estructurales entre los territorios de las latitudes superiores de Europa y la Hispania -sobre todo en la supraestructura de la organización política y en la gestión de la tierra- podemos entender que las pautas de comportamiento político de los reyes visigodos y los caudillos del Norte podrían tener razgos en común, sobre todo los aspectos de la negociación, el reparto del botín y el fortalecimiento de los vínculos de lealtad. La descripción realizada por Wickham sobre las relaciones de subordinación y mando entre los líderes y los seguidores deberían inspirar los próximos análisis basados en evidencias empíricas.

Para finalizar este apartado podemos decir que la caracterización realizada por Halsall sobre las relaciones laxas desarrolladas entre los líderes militares y sus subordinados y las observaciones sobre los reyezuelos norteños de Wickham, planteos inspirados en la literatura antropológica, que permiten pensar la relación jefe militar - soldado visigodo en un sistema de clientelas desde una nueva perspectiva, cuya principal característica es que el nexo existente entre las partes sería mucho más laxo de lo que la historiografía seguidora de Barbero y Vigil y la corriente continuista suponen y que los hombres libres podrían cambiar de jefe, incluso si éste era el rey. Esto no significa que desconozcamos la existencia de dependientes serviles en la filas del ejército visigodo, sino que debemos empezar a estudiar la composición social de las milicias con el propósito de poder

\footnotetext{
${ }^{56}$ WICKCHAM, Chris - Una historia nueva de la alta edad media. op. cit. Ver capítulo 6.
} 
entender las distintas naturalezas de los vínculos políticos y de subordinación que existían en el seno del ejército visigodo.

\section{Balance}

El camino historiográfico recorrido nos enseña las diferentes interpretaciones existentes sobre la organización y composición social del ejército visigodo. Es necesario este tipo de análisis, pues permite observar los orígenes de las afirmaciones de los autores contemporáneos; también revela que en los trabajos visitados subyacen en diferentes grados de conciencia (o de inconciencia) las grandes narrativas historiográficas; ayuda a reflexionar sobre los argumentos de los autores, discutirlos, desechar algunos o aceptar total o parcialmente otros; $\mathrm{y}$, sobre todo, posibilita involucrarnos en la discusiones eruditas en torno a los aspectos más controversiales de las fuentes.

Sintetizando los aspectos historiográficos del problema del ejército, es evidente entonces que los ejes dicotómicos centrales que discuten los especialistas son: si existió un único cuerpo militar godo permanente de carácter público o uno integrado por tropas aportadas por la aristocracia de forma temporal y privada (por lo tanto, si la estructura era decimal o territorial y la importancia y el número de los guerreros a caballo); si la convocatoria a las filas militares solo incumbía a los hombres libres de estirpe visigoda o también a los provinciales romanos y, de aceptar esto último, de cuándo data la integración; y si la forma de pago del ejército se efectuaba bajo el antiguo sistema imperial de la annona o si el rey entregaba concesiones de tierras y bienes, sobre esto último se discute fuertemente el carácter pleno o beneficial de aquellas. Las fuentes sobre el ejército, principalmente las leyes civiles que lo regulan, fueron el centro de este debate. Para los autores estudiar las disposiciones sobre las concesiones de tierras o bienes entregados por el rey a la aristocracia como retribución por participar en asuntos de gobierno y en la guerra y descubrir el carácter pleno o beneficial de dichas concesiones es clave para entender el problema del ejército y la sociedad toledana.

Algunos viejos problemas historiográficos, como la data de la incorporación de los romanos al ejército godo, han ido perdiendo su lugar principal frente a otro que se convirtió en el eje de las discusiones de los últimos años. Nos referimos a los debates en 
torno al pago de los soldados: si se concretaba con lo recaudado por los impuestos o a través de la entrega de tierras. Como ya hemos visto, este aspecto es clave para pensar de una u otra manera la caracterización general del periodo temprano medieval.

De acuerdo con las consideraciones que se hemos venido realizando, estamos en condiciones de decir que la historiografía no brinda respuestas satisfactorias al problema de la organización y composición social del ejército visigodo. En parte se debe al tratamiento dispensado a la documentación y por los marcos teóricos utilizados, y por otra se debe a la poca cantidad de páginas dedicadas al análisis del ejército visigodo. Este fenómeno puede ser explicado solo si comprendemos el problema de las tradiciones historiográficas.

En primer lugar, debemos entender que el reino visigodo es -y ha sido, en gran medidaun elemento fundacional de la "Gran Narrativa" nacionalista española, la partícula primigenia de la esencialidad hispánica presente en autores seminales de la historiografía ibérica, el lugar común a donde retrotraen los orígenes de su nación. Correlativamente, el hecho de que la historiografía por fuera de España, durante una gran fracción del siglo XX, le brinde un espacio reducido al estudio de los visigodos es (en parte) consecuencia del fenómeno de las tradiciones historiográficas o visiones nacionales, que se preocupan por buscar soluciones a los problemas peculiares de sus cunas a partir de la investigación en torno a los primeros siglos de la Edad Media. Como consecuencia se produce una literatura histórica cobijada en ámbitos de discusión nacional; el método comparativo raramente es empleado como contraprueba de los resultados obtenidos, afirmando aún más la tendencia localista de los estudios. Asimismo, creemos que parte de esta exigua producción es resultado de la fuerte influencia de los historiadores más importantes (sin dudas Barbero y Vigil, Thompson, King y, por supuesto, Sánchez Albornoz) sobre el horizonte historiográfico actual; sus conclusiones han sido para los investigadores contemporáneos grilletes analíticos.

Es notable cómo las tesis opuestas de Sánchez Albornoz y de Barbero y Vigil siguen marcando la arquitectura de los estudios (ya sean de origen hispano o no) sobre el ejército, cuyo análisis, de manera sorprendente, es casi inexistente. También es destacable la falta de perspectivas inspiradas por elementos provenientes de la 
antropología. Es sorprendente porque el análisis del ejército revela mecanismos fundamentales del ejercicio del poder regio; es sorprendente también porque su examen -si bien difícil por los tipos de fuentes- puede esclarecer problemas relacionados con la naturaleza de los vínculos políticos entre los hombres libres y la aristocracia y los distintos grados de dependencia y subordinación; observar la organización fiscal del reino y, sobre todo, profundizar sobre la inestabilidad política del reino. En suma, un análisis sobre el ejército podría brindar las claves para entender el funcionamiento de las relaciones sociopolíticas del reino de Toledo.

\section{Referências bibliográficas:}

ARCE, Javier -Esperando a los árabes: los visigodos en Hispania (507-711). Madrid: Marcial Pons Historia, 2011.

ASTARITA, Carlos - "Visiones nacionales en el medievalismo". in - Anales de Historia Antigua, Medieval y Moderna. Buenos Aires, 2008, vol. 40, pp. 119-150,

BARBERO, Abilio \& VIGIL, Marcelo -La formación del feudalismo en la Península Ibérica. Barcelona: Crítica, 1978.

COLLINS, Roger - La España Visigoda 409-711. Barcelona: Crítica, 2005.

DÍAZ MARTÍNEZ, Pablo. C - "La dinámica del poder y la defensa del territorio: para una comprensión del fin del reino visigodo de Toledo". in - XXXIX Semana de Estudios Medievales, de Mahoma a Carlomagno, Estella, 2012, pp. 167-205.

DÍAZ MARTÍNEZ, Pablo - Hispania tardoantigua y visigoda. Madrid: Istmo, 2007.

DOPSCH, Alfons - Fundamentos económicos y sociales de la cultura europea (de César a Carlomagno). México: Fondo de Cultura Económica, 1986.

FERREIRO, Alberto - The Visigoths in Gaul and Spain (a.D. 418- 711). A bibliography, Leiden: Brill, 1988. 
FERREIRO, Alberto - The Visigoths in Gaul and Iberia. A Supplemental Bibliography, 1984-2003. - The Visigoths in Gaul and Iberia (Update). A Supplemental Bibliography, 2004-2006. - Brill Publishing (The Medieval and Early Modern Iberian World, 28 y 35).- Leiden-Boston, 2006.

FERREIRO, Alberto - The Visigoths in Gaul and Iberia (Update). A Supplemental Bibliography, 2007-2009. Leiden: Brill, 2011.

FERREIRO, Alberto - The Visigoths in Gaul and Iberia (Update). A Supplemental Bibliography, 2010-2011. Leiden: Brill, 2014.

FRIGHETTO, Renan -“O problema da legitimidade e a limitaçao do poder régio na Hispania visigoda: o reinado de Ervígio (608-687)". in -Gerión, 2004, nº 1, pp 421-435.

FRIGHETTO, Renan - "Infidelidade e Barbárie na Hispania Visigoda". in - Gerión, Vol. 20, N 1, 2002, pp. 491-510.

GARCÍA MORENO, Luis, A - Historia de España visigoda. Madrid: Cátedra, 1989.

HALSALL, Guy - Warfare and society in the Barbarian West, 450-900. Londres: Routledge, 2003.

ISLA FREZ, Amancio - Ejército, sociedad y política en la Península Ibérica entre los siglos VII y XI. Madrid: CSIC, 2010.

KING, P.D - Derecho y sociedad en el reino visigodo. Madrid: Alianza, 1972.

LORING, María. I., PÉREZ, Dionisio. y FUENTES, Pablo - La Hispania tardorromana y visigoda, siglos V-VIII. Madrid: Editorial Síntesis, 2007.

LORING, María, I. y FUENTES HINOJO, Pablo-"Esclavitud y servidumbre en el tránsito del mundo antiguo al medieval". in - "Romanización" y "reconquista" en la Península Ibérica: nuevas perspectivas, 1998, pp. 247-256. 
MARTIN, Céline -La géographie du pouvoir dans l'Espagne visigothique. Francia: Universitaires du Septentrion, 2003.

ORLANDIS, José - Historia del reino visigodo español. Madrid: RIALP, 2011.

PÉREZ SÁNCHEZ, Dionisio - El ejército en la sociedad visigoda. Salamanca: Ediciones de la Universidad de Salamanca, 1989.

PETERSEN, Leif, I - Siege warfare and military organization in the successor states (400-800). Byzantium, the West and Islam, (History of warfare; volume 91), LeidenBoston: Brill, 2013.

SALRACH, Joseph. M - "Del estado romano Principales tendencias historiográficas sobre la organización militar visigoda del reino de Toledo a los reinos germánicos: en torno a las bases materiales del poder del estado en la antigüedad tardía y la Alta Edad Media”. in De la antigüedad al Medievo: siglos IV-VIII. 1993, pp .95-142

SÁNCHEZ ALBORNOZ, Claudio - En torno a los orígenes del feudalismo. Mendoza, 1942

SÁNCHEZ ALBORNOZ, Claudio - "Pervivencia y crisis de la tradición jurídica romana en la España goda", en Viejos y nuevos estudios sobre las instituciones medievales españolas. II, Madrid, 1976.

SÁNCHEZ ALBORNOZ, Claudio - "El precarium en Occidente durante los primeros siglos medievales". Viejos y nuevos estudios sobre las instituciones medievales españolas. II, Madrid, 1976.

SÁNCHEZ ALBORNOZ, Claudio - El «Stipendium»Hispano-Godo y los orígenes del beneficio prefeudal. Buenos Aires: Instituto de Investigaciones Históricas. Departamento de Historia de España, 1947

SÁNCHEZ ALBORNOZ, Claudio - "España y el feudalismo carolingio". Viejos y nuevos estudios sobre las instituciones medievales españolas. II, Madrid, 1976.

Medievalista online № 19| Janeiro - Junho 2016 @ IEM - Instituto de Estudos Medievais 22 
SÁNCHEZ ALBORNOZ, Claudio - “¿Donaciones reales restringidas en la España goda y postvisigoda?" Separata Homenaje a Don José María Lacarra de Miguel en su jubilación del profesorado. Vol. I, Zaragoza 1977.

SÁNCHEZ ALBORNOZ, Claudio - SÁNCHEZ ALBORNOZ, Claudio - "El ejército visigodo: su protofeudalización”. Investigaciones y documentos sobre las instituciones hispana. Santiago: Edit. Jurídica de Chile, 1970, pp. 5-56. p.7.

SMITH, Katherine, A. - War and the Making of Medieval Monastic Culture. Suffolk: The Boydell Press, 2013.

THOMPSON, Edward. A - The goths in Spain. Oxford: Oxford University Press, 1969. TORRES LÓPEZ, Manuel - "El estado visigótico”. Anuario de Historia del Derecho Español, T.III, 1926, pp.304-475

TORRES LÓPEZ, Manuel - Lecciones de historia del Derecho. Salamanca, 1934.

VALVERDE CASTRO, María. R - Ideología, simbolismo y ejercicio del poder real en la monarquía visigoda: un proceso de cambio. Salamanca: Ediciones de la Universidad de Salamanca, 2000

WICKHAM, Chris - Una historia nueva de la Alta Edad Media, Europa y el mundo mediterráneo, 400-800. Barcelona: Crítica, 2008. WICKHAM, C - El legado de Roma. Una historia de Europa de 400 al 1000, Barcelona: Ed. Pasado y Presente, 2013.

WICKHAM, Chris - "Tradiciones nacionales y el problema de la comparación”. in Anales de Historia Antigua, Medieval y Moderna.Buenos Aires, 2008, vol. 40, pp. 1124.

WICKHAM, Chris - "Problems of comparing rural societies in early medieval western Europe". in - Land \& Power, Studies in Italian and European Social History, 400-1200. London: British School at Rome, 1994, p. 201 y ss; Versión en español: "Problemas de comparación de sociedades rurales en la Europa occidental de la temprana Edad Media”. in -Anales de Historia Antigua y Medieval, Buenos Aires, 1996, vol. 29, pp. 45 y ss.

Medievalista online $N^{\circ} 19 \mid$ Janeiro - Junho 2016 @ IEM - Instituto de Estudos Medievais 23 


\section{COMO CITAR ESTE ARTIGO}

\section{Referência electrónica:}

ORLOWSKI, Sabrina Soledad - "Principales tendencias historiográficas sobre la organización militar visigoda del reino de Toledo".

Medievalista [Em linha]. №19 (Janeiro - Junho 2016). [Consultado dd.mm.aaaa].

Disponível em

http://www2.fcsh.unl.pt/iem/medievalista/MEDIEVALISTA19/orlowski1904.html ISSN 1646-740X.

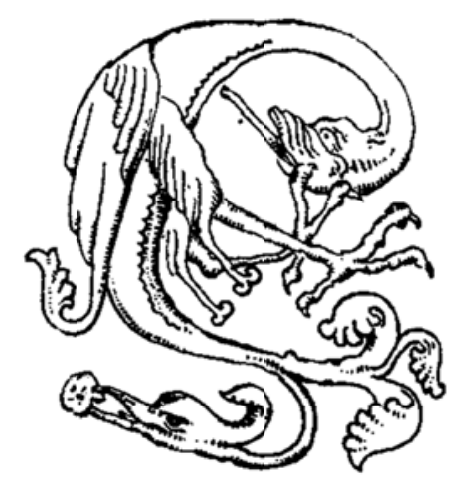

Medievalísta online NN 19| Janeiro - Junho 2016 (c) IEM - Instituto de Estudos Medievais 24 